\title{
Invasive sphenoid sinus aspergillosis mimicking sellar tumor: a report of 4 cases and systematic literature review
}

\author{
Hanwen Zhang ${ }^{1,2}$, Nian Jiang ${ }^{1}$, Xuelei Lin', Siyi Wanggou', Jeffrey J. Olson² and Xuejun Li ${ }^{1 *}$
}

\begin{abstract}
Background: Invasive sphenoid sinus aspergillosis is a rare but life-threatening condition usually found in immunocompromised patients. When involving cavernous sinus and surrounding structures, patients are frequently misdiagnosed with a neoplasm or sellar abscess. Timely diagnosis and intervention are crucial to patients' outcomes. The objective of this study is to review cases of invasive sphenoid sinus aspergillosis to describe disease manifestations, imaging features, treatment, and outcome.

Case presentation: We describe four patients with invasive sphenoid sinus aspergillosis misdiagnosed as sellar tumors preoperatively. The mass was completely removed in three patients and partially removed in one patient microscopically. Pathological examinations confirmed Aspergillus in all cases. All four patients received anti-fungal agents postoperatively. There was no recurrence at the time of each patient's follow-up date. One patient with complete resection was lost to follow-up while the other three patients' neurologic function improved. Additionally, we performed a systematic review regarding invasive sphenoid sinus aspergillosis of existing English literature.
\end{abstract}

Conclusion: With regard to clinical symptoms, headache, vision impairment, and ophthalmoplegia were observed in over half of the patients in the literature. A sellar mass with bone destruction on $C T$ and involvement of cavernous sinus is highly suggestive of invasive fungal sphenoid sinusitis. Immediate surgical removal of the lesion is recommended for invasive sphenoid sinus aspergillosis to preserve nerve function and increase the likelihood of survival.

Keywords: Invasive fungal sinusitis, Cavernous sinus syndrome, Intracranial aspergillosis, Sphenoid sinus infection, Sellar mass, Imaging features, Prognosis

\section{Background}

Intracranial aspergillosis is an extremely rare but lifethreatening disease. Aspergillus can reach the central nervous system (CNS) by three different routes [1]. When it directly spreads from sphenoid sinus to cavernous sinus, patients are frequently misdiagnosed with a neoplasm or sellar abscess due to the lack of specificity on radiological images. Without proper

\footnotetext{
*Correspondence: Ixjun70s@163.com

${ }^{1}$ Department of Neurosurgery, Xiangya Hospital, Central South University, 87 Xiangya Road, Changsha 410008, Hunan, People's Republic of China

Full list of author information is available at the end of the article
}

intervention, the mortality rate can be as high as $80 \%$ [2]. It is imperative to realize that accurate diagnosis is crucial for patients to achieve a better prognosis [3]. The current treatment of intracranial aspergillosis usually comprises a combination of surgical debridement and antifungal medication $[4,5]$. However, a retrospective evaluation and summary of the outcomes reported in the literature is needed to guide further clinical intervention. The aim of this study is to analyze the radiological features and treatment options so as to evaluate their effect on outcomes of invasive sphenoid sinus aspergillosis. 


\section{Case presentation}

\section{Case 1}

A 69-year-old male was admitted with a progressive frontal paroxysmal headache accompanied with mild vomiting, diplopia, and visual disturbance for 1 month, without fever. Visual acuity was 0.6 in the left eye and 0.9 in the right eye without visual field loss. Other neurologic and clinical findings were normal. He was healthy other than a 10-year history of well-controlled hypertension and coronary heart disease. The patient reported no history of fungal infection or a history of contact with unusual infectious sources. CT scan showed a mass in the sphenoid sinus and clival region. Bone destruction was observed in both regions (Fig. 1a). MRI showed a hypointense signal on T2-weighted images (T2WI) in the lesions and an isointense signal on T1 weighted images (T2WI) with heterogeneous gadolinium-enhancement in the sphenoid sinus, both cavernous sinuses, bilateral ethmoid sinuses, and maxillary sinus (Fig. 1b-d). This patient underwent transsphenoidal lesion debridement. Purulence was observed during the operation. A biopsy was performed immediately and histopathology examination revealed Aspergillus species (Fig. 1e). The patient was administered fluconazole after surgery. Post-operative neurological examination showed obvious improvement of headache, vomiting, vision, and diplopia. Post-operative images indicated the resection of the mass (Fig. 1f). Examination after a follow-up period of 24 months showed no clinical symptoms, and no additional therapy was required.
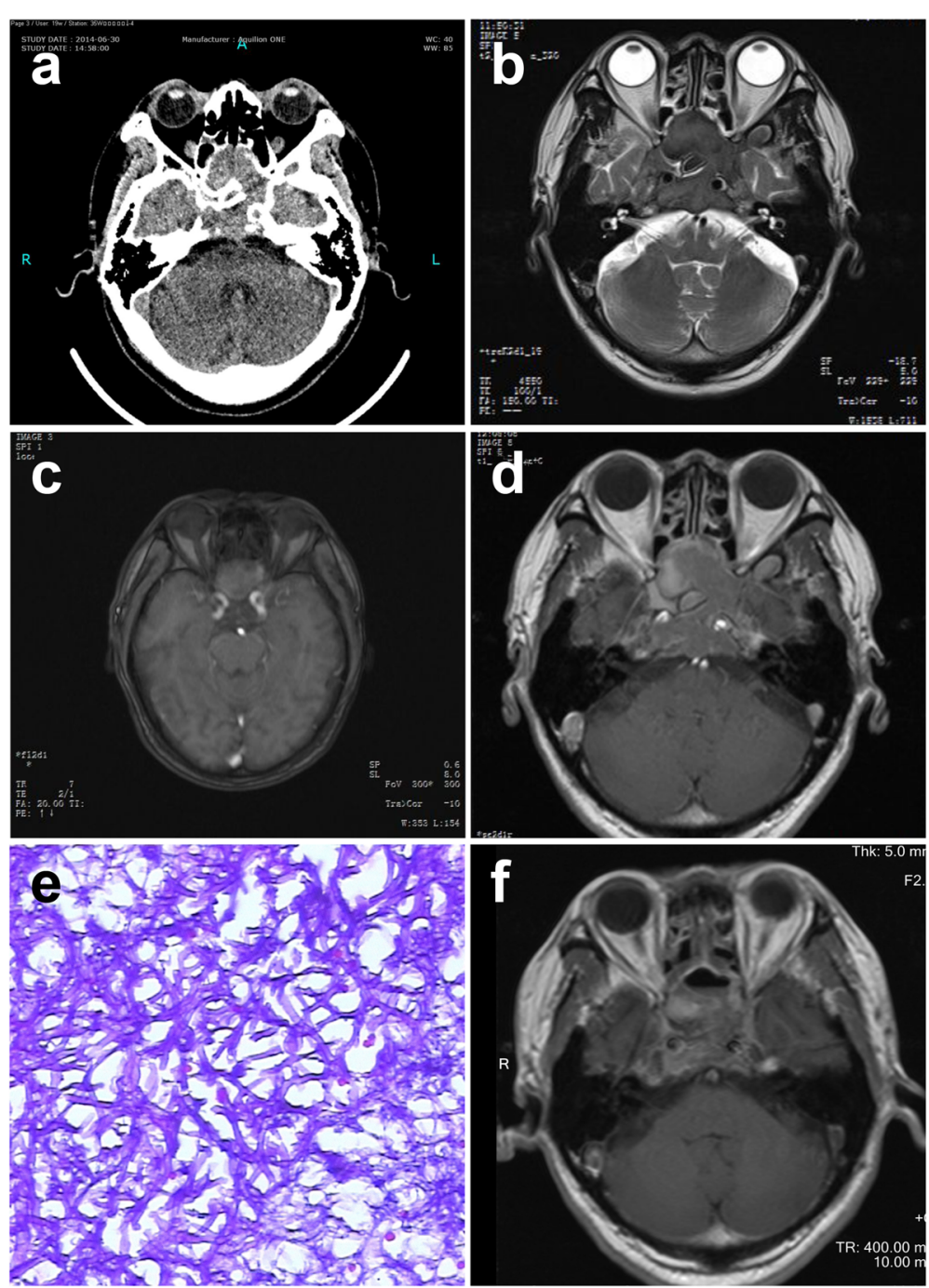

Fig. 1 Case 1: a 69-year-old man. a CT image showing bone destruction in the sphenoid sinus and clival region. b MRI showing an intrasellar mass with hypointense signal on T2WI. c MRI showing an intrasellar mass with isointense signal on T1WI. $\mathbf{d}$ Enhanced MRI showing the lesions with heterogeneous enhancement in sphenoid, bilateral cavernous sinuses, ethmoid sinuses, and maxillary sinus. e Photomicrograph of the surgical specimen revealing the histologic findings of septate, clustered aspergillus hyphae. $\mathbf{f}$ MRI showing the resection of the mass 


\section{Case 2}

A 52-year-old male was admitted with a paroxysmal headache in the right parietal region accompanied by visual disturbance in the right eye for over 2 months. Both symptoms mostly occurred in the morning and could be partially relieved with ibuprofen. He had a 2-year history of diabetes mellitus type 2 well controlled with metformin and repaglinide. He was afebrile and neurological examination was unremarkable. CT scan showed a mass in sphenoid sinus and cavernous sinus with bone destruction (Fig. 2a). MRI showed a $20 \times 25 \mathrm{~mm}$ circular intrasellar mass with hyperintensity T1WI and T2WI, heterogeneously gadolinium-enhancement, and adjacent meningeal enhancement. The lesion extended bilaterally into the cavernous sinus and formed a $12 \times 11 \mathrm{~mm}$ mass (Fig. $2 \mathrm{~b}-\mathrm{d}$ ). The patient underwent a trans-sphenoidal mass excision and debridement. The lesion was solid and cystic with yellow-brown fluid and a gray wax-like solid component. A biopsy was performed immediately and histopathologic examination revealed Aspergillus species (Fig. 2e). Postoperative physical and neurological examination showed obvious improvement of headache and visual disturbance. Post-operative images indicated the resection of the mass (Fig. 2f). Examination after a follow-up of 20 months showed no clinical symptoms.

\section{Case 3}

A 64-year-old male had experienced a paroxysmal pain in the frontal region and left nose radiating to the occipital region for 7 months. The patient also reported progressive paresthesia on the left cheek and rapidly decreasing visual acuity in the left eye. Neurological examination revealed a
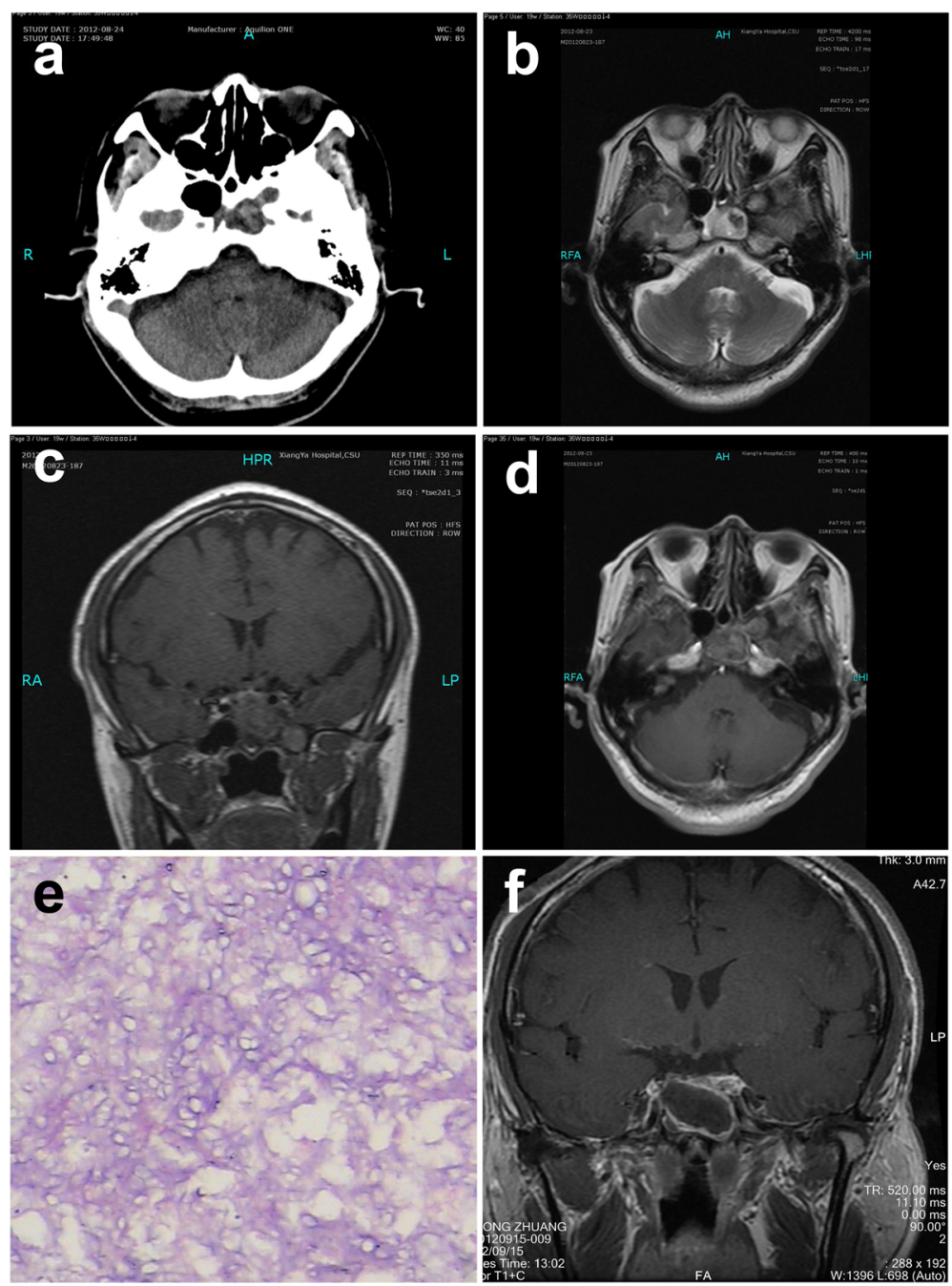

Fig. 2 Case 2: a 52-year-old man. a CT image showing bone destruction in the sphenoid sinus and cavernous sinus region. b MRI showing an intrasellar mass with hyperintense signal extending bilaterally into the cavernous sinus on T2WI. c MRI showing an intrasellar mass with hyperintense signal on T1WI. d Enhanced MRI showing the lesions ring enhancement. e Photomicrograph of the surgical specimen revealing the histologic findings of septate, clustered aspergillus hyphae. $\mathbf{f}$ MRI showing the resection of the mass 
left-sided ptosis as the only new finding. Interestingly, body temperature (axillary) fluctuated between $36.1{ }^{\circ} \mathrm{C}$ and $38.4^{\circ} \mathrm{C}$. The patient denied a history of other diseases. Physical examination showed no light perception or reflex was detected in the left eye. His pupils were $3 \mathrm{~mm}$ on the right and $4 \mathrm{~mm}$ on the left. CT showed an isodense lesion in the region of the left cavernous sinus, left orbital apex, left optic nerve canal, and sphenoid sinus. Bone destruction was seen in the left wall of the sphenoid sinus (Fig. 3a). MRI showed a $33 \times 16 \mathrm{~mm}$ isointense lesion in both T1WI and T2WI of the left optic canal region and extending into the orbit. Enhanced-MRI showed ring enhancement of the lesion. Lesions with hyperintense T2weighted signal were seen in paranasal sinuses (Fig. 3b-d). The patient was self-treated with anti-infectious medication but his headache increased in intensity, frequency, and duration. The patient underwent mass excision of the mass via pterional craniotomy. Cream-like liquid amidst a gray growth was observed in the left cavernous sinus. A biopsy was performed immediately, and histopathologic examination revealed an Aspergillus species (Fig. 3e). Postoperative images indicated the resection of mass (Fig. 3f). The patient received voriconazole after surgery. However, he was lost to follow-up.

\section{Case 4}

A 50-year-old female was admitted with a paroxysmal boring pain in the left parietal and left frontal region for 9 months, accompanied by progressive vomiting and decreasing of visual acuity and proptosis in the left eye. Headache could be relieved by diclofenac sodium. Two months prior to presentation, her headache worsened extending to the
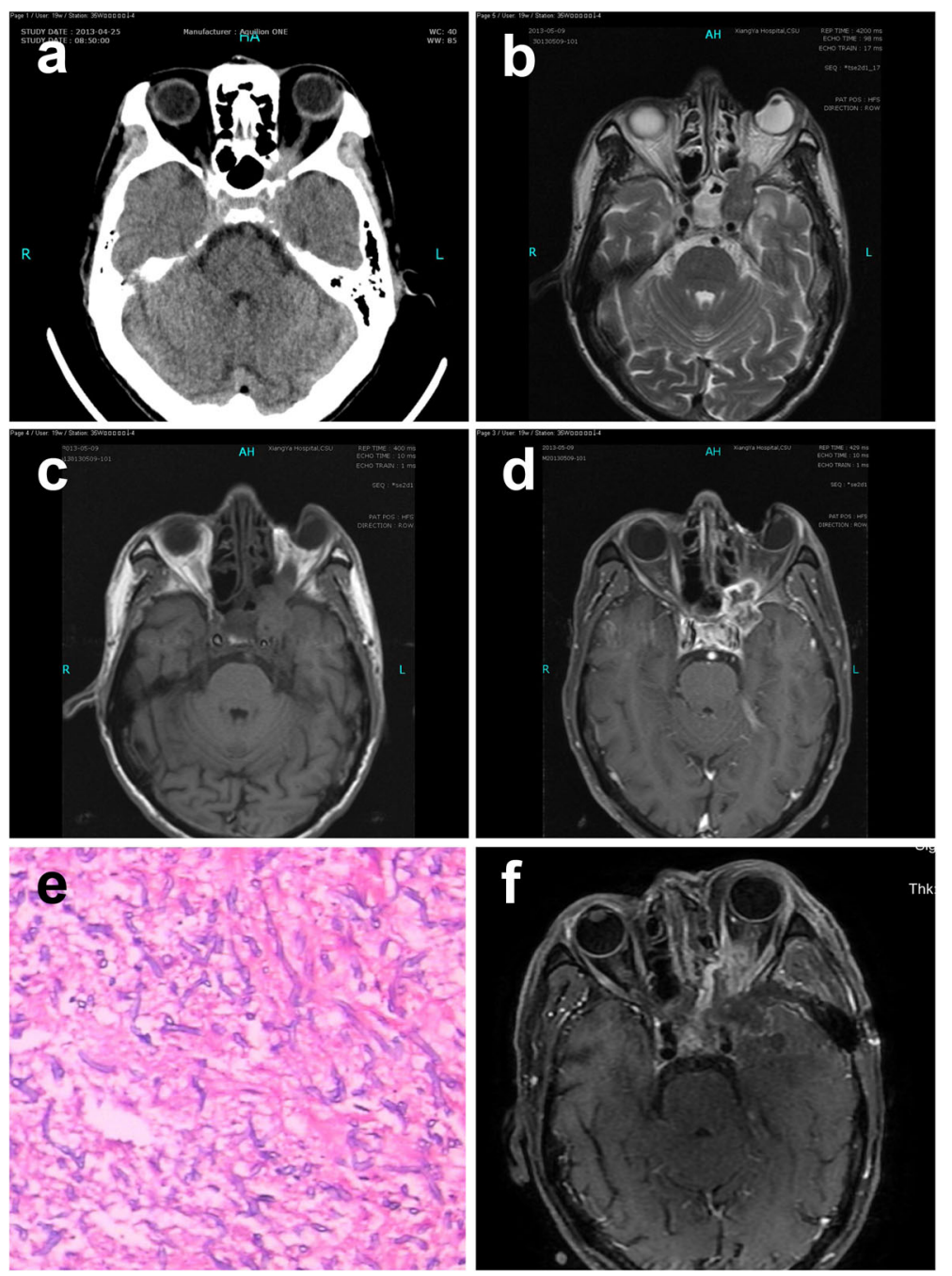

Fig. 3 Case 3: a 64-year-old man. a CT image showing bone destruction in the left wall of the sphenoid sinus. b MRI T2WI showing $33 \times 16 \mathrm{~mm}$ hypo-isointense lesion in both on the left optic canal region and extending into the orbit. c MRI T1WI showing an isointense signal of the lesion. d Enhanced MRI showing ring enhancement of the lesion. e Photomicrograph of the surgical specimen revealing the histologic findings of the septate, clustered aspergillus hyphae. $\mathbf{f}$ MRI showing the resection of the mass 
whole left side of the face, accompanied by numbness. No light perception or reflex was detected in the left eye. Horizontal movement was limited in the left eye. Pre-operative CT showed a $29 \times 20 \mathrm{~mm}$ isodense lesion with heterogeneously enhancement in the region of the left cavernous sinus, left orbital apex, left optic nerve canal, and sphenoid sinus. Bone destruction could be seen in the left wall of the sphenoid sinus. The optic nerve could not be distinguished from the lesion (Fig. 4a). MRI showed a $21 \times 26 \mathrm{~mm}$ patchy lesion that was isointense on T1WI and hyperintense on T2WI in the left cavernous sinus region (Fig. 4b, c). Enhanced-MRI showed noticeable enhancement of the lesion. The lesion was closely related to the dura mater and extended to the sphenoid sinus and optic apex, partly surrounding the left internal carotid artery (Fig. 4d). MRA suggested stenosis in the cavernous segment of the left internal carotid artery and A1 segment of the left anterior cerebral artery. The patient underwent partial mass excision via a pterional craniotomy due to its close attachment to the ophthalmic branch and maxillary branch of the trigeminal nerve. The lesion was partly fibrotic and partly a milk-white viscous substance. A biopsy was performed immediately and histopathologic examination revealed Aspergillus species (Fig. 4e). The patient was administered voriconazole after surgery. Post-operative images indicated the resection of the mass (Fig. 4f). Examination after a follow-up of 15 months showed a complete resolution of the headache. Her vision of the left eye was not regained.
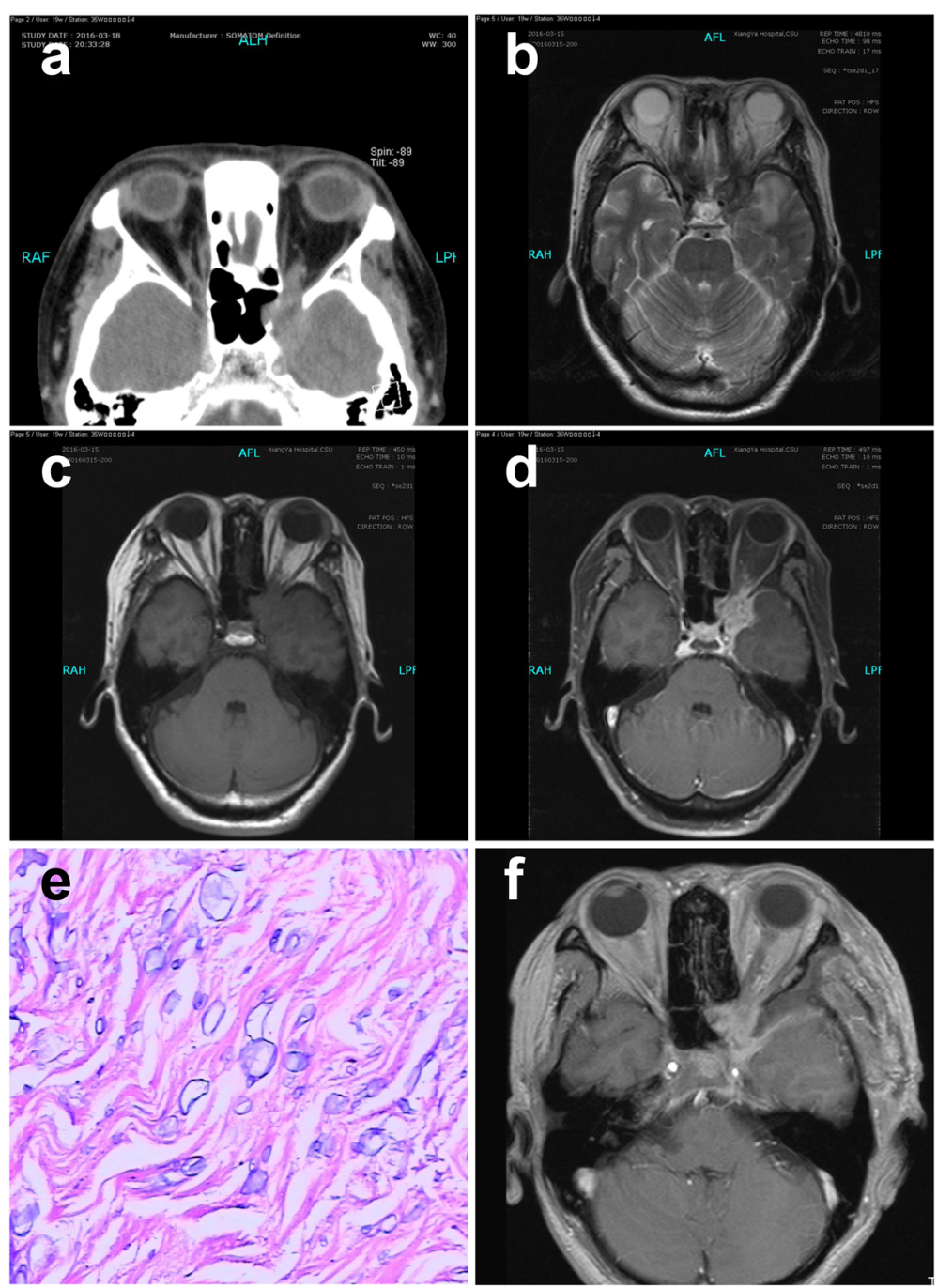

Fig. 4 Case 4: a 50-year-old woman. a CT image showing an isodense lesion within the region of the left cavernous sinus left orbital apex, left optic nerve canal, and sphenoid sinus, with bone destruction in the left wall of the sphenoid sinus. $\mathbf{b}$ MRI showing a patchy lesion with the hyperintense signal on T2WI in the left cavernous sinus region. c MRI T1WI showing an isointense signal of the lesion. $\mathbf{d}$ Enhanced MRI showing noticeable enhancement of the lesion. e Photomicrograph of the surgical specimen revealing the histologic findings of septate, clustered aspergillus hyphae. $\mathbf{f}$ MRI showing the resection of the mass 


\section{Systematic literature review}

A total of 42 publications were extracted from the literature for analysis. In those studies, 68 patients were found with pathologically confirmed Aspergillus fumigatus. The median number of patients in each study was 1 (range, 1-6). See Table 1 for a list of included studies and patient demographics. The mean patient age was 59 (range $8-82)$ years, and $38(58.5 \%)$ patients were male. Thirty (44.1\%) patients were found to be immunocompromised.

The most common symptom was headache $(n=68$, $61.8 \%$ ), followed by vision impairment/loss (57.4\%), ophthalmoplegia $(54.4 \%)$, facial/orbital pain (30.9\%), and exophthalmos (30.0\%). The complete listing of clinical presentations was summarized in Table 2.

The radiologic findings were found in some of the papers. Forty-seven cases included MRI results (T1WI $n=47$, T2WI $n=42$ ) and 41 cases included CT results. Among all patients, hypointense T1-weighted and hypointense T2weighted were most common. Over half $(n=47,53.2 \%)$ of the cases found an enhancement in T1WI. Bone destruction was observed on CT in 32 (78.0\%) patients. Fifty-five cases out of 68 demonstrated treatment and prognosis. Surgery was performed in 37 (67.3\%) patients and antifungal drugs were administrated in $48(87.3 \%)$ patients. Amphotericin B $(n=55,40 \%)$ and voriconazole $(40 \%)$ were the most popular choice for antifungals. Despite the treatment, only $27(50 \%)$ patients achieved complete recovery and 17 patients (31.5\%) died from the disease.

\section{Discussion}

In the pre-antibiotic era, the mortality rate of acute fulminant invasive fungal sinusitis was $50-80 \%$ [2]. Invasive fungal sphenoid sinusitis is more aggressive than invasive fungal infection of the other paranasal sinuses due to the involvement of important surrounding structures (e.g., cavernous sinus, pituitary gland, internal carotid artery, and cranial nerves II, III, IV, V1, V2, and VI). Clinical manifestations of significance include superior orbital fissure syndrome, orbital apex syndrome and cavernous sinus syndrome $[45,46]$. When the infection spreads to the cavernous sinus, cranial neurologic and ophthalmologic symptoms may occur. Patients are usually asymptomatic during the early stages of the disease but are frequently misdiagnosed as a neoplasm or sellar abscess due to the lack of specificity on radiological images when it progresses. Takahashi et al. have found plasma $B$-D-glucan levels are one of the most sensitive markers of deep fungal infection in patients with intracranial aspergillosis. However, these findings were not verified by other studies [5]. The low prevalence, atypical modes of onset and presentation, and low positive rate of Aspergillus in blood and CSF cultures also contribute to the difficulty of diagnosis [8]. Early diagnosis and proper intervention are crucial for patients to achieve a better prognosis [3].
Table 1 Systematic literature review of cavernous sinus syndrome caused by Aspergillus

\begin{tabular}{|c|c|c|c|c|c|}
\hline & Author & Year & Number & Age & Male \\
\hline 1 & Kumar [6] & 2017 & 8 & 33.8 & 5 \\
\hline 2 & Rosenvald [7] & 2016 & 1 & 55 & 0 \\
\hline 3 & Wang [8] & 2017 & 5 & 40.2 & 1 \\
\hline 4 & Brenet [9] & 2016 & 1 & 75 & 1 \\
\hline 5 & Neil [10] & 2016 & 1 & 69 & 1 \\
\hline 6 & Chi [11] & 2014 & 1 & 55 & 1 \\
\hline 7 & Singh [12] & 2014 & 1 & 68 & 1 \\
\hline 8 & Horowitz [13] & 2013 & 1 & 57 & 1 \\
\hline 9 & Chan [14] & 2012 & 1 & 64 & 1 \\
\hline 10 & McClelland [15] & 2012 & 1 & 60 & 1 \\
\hline 11 & Lee [16] & 2012 & 1 & 73 & 1 \\
\hline 12 & Furtado [17] & 2011 & 1 & 30 & 1 \\
\hline 13 & Takahashi [5] & 2011 & 4 & 67.8 & 2 \\
\hline 14 & Yan [18] & 2011 & 1 & 56 & 1 \\
\hline 15 & Al-radadi [19] & 2011 & 1 & 35 & 0 \\
\hline 16 & Saini [20] & 2010 & 6 & 45 & 2 \\
\hline 17 & Wipfler [21] & 2009 & 1 & 68 & 1 \\
\hline 18 & Cheung [22] & 2009 & 1 & 49 & 1 \\
\hline 19 & Chua [23] & 2008 & 2 & 41 & 1 \\
\hline 20 & Sasindran [24] & 2008 & 1 & 8 & 1 \\
\hline 21 & Akhaddar [25] & 2007 & 1 & 62 & 1 \\
\hline 22 & Freudenstein [26] & 2007 & 1 & 66 & 1 \\
\hline 23 & Baumann [27] & 2007 & 3 & / & / \\
\hline 24 & Stodulski [28] & 2006 & 1 & 65 & 1 \\
\hline 25 & Browning [4] & 2006 & 1 & 83 & 0 \\
\hline 26 & Chopra [29] & 2006 & 1 & 66 & 0 \\
\hline 27 & Pinzer [30] & 2006 & 1 & 59 & 0 \\
\hline 28 & Siraj [31] & 2005 & 1 & 62 & 1 \\
\hline 29 & Deveze [32] & 2005 & 2 & 62 & 0 \\
\hline 30 & Urculo [33] & 2005 & 1 & 65 & 0 \\
\hline 31 & Petrick [34] & 2003 & 1 & 74 & 1 \\
\hline 32 & Safdar [35] & 2002 & 1 & 68 & 0 \\
\hline 33 & Endo [1] & 2001 & 1 & 55 & 1 \\
\hline 34 & Hurst [36] & 2001 & 1 & 73 & 1 \\
\hline 35 & Chandra [37] & 2000 & 3 & 38.7 & 0 \\
\hline 36 & Imai [38] & 1999 & 1 & 47 & 1 \\
\hline 37 & Takahashi [39] & 1998 & 1 & 78 & 1 \\
\hline 38 & Carta [40] & 1998 & 1 & 73 & 1 \\
\hline 39 & deShazo [41] & 1997 & 2 & 61.5 & 1 \\
\hline 40 & Breadmore [42] & 1994 & 1 & 71 & 1 \\
\hline 41 & Fujiwara [43] & 1989 & 1 & 60 & 1 \\
\hline 42 & Rowed [44] & 1985 & 1 & 82 & 1 \\
\hline
\end{tabular}


Table 2 Clinical findings of 68 patients

\begin{tabular}{ll}
\hline Headache & $42(61.8 \%)$ \\
Vision impairment/loss & $39(57.4 \%)$ \\
Ophthalmoplegia & $37(54.4 \%)$ \\
Facial/orbital pain & $21(30.9 \%)$ \\
Exophthalmos & $19(30.0 \%)$ \\
Diplopia & $11(26.2 \%)$ \\
Ptosis & $11(26.2 \%)$ \\
Altered sensorium & $9(13.2 \%)$ \\
Hemiparesis & $4(5.9 \%)$ \\
Weakness & $3(4.4 \%)$ \\
Mydriasis & $3(4.4 \%)$ \\
Rhinorrhea & $1(1.5 \%)$ \\
Eyelid drooped & $1(1.5 \%)$ \\
Horner & $2(1.5 \%)$ \\
Orbital apex involved & $28(41.2 \%)$ \\
\hline
\end{tabular}

\section{Presentation and physical examination}

The early clinical symptoms of acute fulminant invasive fungal sinusitis include nasal obstruction, rhinorrhea, facial pain, headache, proptosis, and diplopia. In our cases, all four patients developed a severe headache and visual disturbance. One patient also had exophthalmos and another experienced altered sensorium. In accordance with previous literature, headache (61.8\%) and visual disturbance (57.4\%) were indeed the most common symptoms seen in patients with invasive sphenoid sinus aspergillosis. Fever is commonly not present. However, abnormal body temperature along with immunocompromised status is highly suggestive.

\section{Imaging characteristics}

Imaging is widely used in neurological diseases but found to be limited in differentiating intracranial aspergillosis from meningiomas, tuberculomas, lymphoid malignancies, and metastasis [20]. Together with our cases, $52.9 \%(n=51)$ of the patients presented enhancement on T1WI. $68.3 \%(n=41)$ of the patients presented with hypo-iso signal intensity on T2WI. For computed tomography imaging, $86.7 \%(n=45)$ were found to have bone destruction. Besides that, soft tissue with enhancement, sclerosis, and calcification of the mass were also found in some patients. On CT images, the fungal mass often appears hyperdense due to calcium salts and metal ions in necrotic areas [47]. Despite the lack of specificity, Kumar et al. concluded that CNS aspergilloma manifests differently in immunocompromised and immunocompetent patients. Reactive resorption to permeative destruction is mostly found in immunocompetent patients. While the mass is often presented as ring-enhancing lesions in immunocompromised patients, it is often presented as focal and thick pachymeningeal enhancement in immunocompetent patients [6]. In conclusion, certain imaging findings such as low signal intensity on T2W images, bone destruction on $\mathrm{CT}$, and the presence of sinus disease with features of fungal infection could be suggestive. In some cases, imaging features like a heterogeneous parenchymal lesion with areas of hemorrhage, infarction, and vascular narrowing or obstruction can also be useful for diagnosis [20].

In addition to conventional imaging studies, DWI is exceptionally useful in differentiating ring-enhancing lesions due to brain abscess from neoplastic lesions [48]. There is a trend of characterizing the etiologic agents on the basis of DWI. Some investigations suggest that DWI appears to be the most sensitive modality for early identifications of cerebral aspergillosis [49-51] \{Friedlander, 2003 \#570\}. Abscesses are usually hyperintense on DWI indicating restricted diffusion, while neoplastic lesions are hypointense or variable [52]. Furthermore, Luthra et al. found possible reliable indications suggesting fungal infection. They concluded that a ring-enhancing T2 heterointense lesion with irregular walls and irregular projections into the cavity with low ADC and no contrast enhancement of these projections carries a high probability of being a fungal abscess [53]. However, the fungal species still needs to be determined with histologic methods.

\section{Differential diagnosis}

A CNS lesion with sinonasal involvement should raise suspicion towards an etiology of neoplasm, inflammation, and infection. Imaging provides limited value in differentiating among infections and a definite diagnosis must be made via biopsy. However, CNS aspergillosis has specific features that differentiate it from others, which are elaborated in this section.

Meningioma can present near the cerebral convexity in the parasagittal region, sphenoid wing, and the juxta sellar area. Rarely, it can arise in the orbit and paranasal sinuses, further extend into cavernous sinus [54]. Both aspergilloma and meningioma appear hyperdense and lead to lytic bone destruction. However, meningioma appears isointense on both T1WI and T2WI. In contrast, aspergilloma appears hypointense on T2WI [55].

Trigeminal schwannoma can also occur in the cavernous sinus and exert a mass effect on adjacent structures. It sometimes contains cystic areas causing heterogeneously enhancement on both MRI and CT, which make it difficult to be distinguished from aspergillosis. However, it is typically hyperintense on T2WI and restricted diffusion is usually not found on DWI [56].

Pituitary adenomas invading the cavernous sinus are rare lesions which can be confused with Aspergilloma clinical wise [57]. The encasement of the ICA is also seen. The mass is typically isotense on T2WI but can be heterogenous and vary in signal due to areas of cystic change, necrosis, or 
hemorrhage [58, 59]. DWI may be applied to assist differentiation as discussed above. Sphenoid sinus ectopic pituitary adenoma is another extremely rare condition. It is usually heterogeneous, demonstrating foci of hypointensity on T1WI and hyperintensity on T2WI [60].

Inflammation of orbital, paranasal sinuses and brain are hypointense on T2WI and may show marked postcontrast enhancement. Bony erosions and destruction are also common in inflammatory diseases [61]. Wegener granulomatosis can mimic and show hypointense T2WI and contrast enhancement on MRI [62]. However, Wegener granulomatosis is a systemic vasculitis. The majority of the patients will have concurrent pulmonary, renal, and skin involvement. Additionally, inflammatory markers and c-ANCA can further exclude the disease.

\section{Treatment and outcomes}

Surgery is the only management treatment method common to all previous publications that significantly change patients' outcomes. Surgical procedure includes the triple aim of diagnosis, cure, and prevention of a recurrence [9]. Decompression of the optic nerve is applied when optic canal is involved. Surgical treatment should also aim at radically removing the infectious mass rather than draining alone [30]. When combined with previous literature, our four cases demonstrate the importance of surgery. $44.4 \%(n=18)$ of the patients without surgery eventually died, while only $24.4 \%$ ( $n=$ 41) of the patients with surgical treatment died from the disease. However, in immunocompromised patients, the risk of operation should be taken into consideration. Anti-fungal usage is also recommended by most studies. Clinically, voriconazole is considered the drug of choice for invasive aspergillosis [25]. Amphotericin and voriconazole are the most widely used; however, there is no relation between drug preference and prognosis. Fungal cavernous sinus infection may further cause a secondary bacterial infection thus anti-bacterial is always applied for precautionary purposes. Cavernous sinus infection is known to possibly lead to inflammatory reaction and hypercoagulability. Whereas, anticoagulation is still controversial $[63,64]$. Current recommendations call for initial intravenous heparin and at least 6 months' treatment of warfarin. The optic nerve is found with the poorest recovery rate.

\section{Conclusion}

Invasive sphenoid sinus aspergillosis is a rare yet lethal condition that commonly presents with headache and visual disturbance. Surgery might not be timely when clinicians misdiagnose it due to its sellar tumor-like character and can cause grave consequences. Here, we meant to gather reported cases to determine specific findings that assist in accurate diagnosis and proper treatment. At least 68 reported cases exist in the English literature, which yielded 72 analyzable cases together with our patients. Overall, both lab tests and radiologic image findings were not specific. However, enhancing T1WI, hypointense T2WI, and boney destruction on CT is highly suggestive of this diagnosis. The involvement of the optic canal and cavernous sinus should raise concern. In addition, DWI could also be considered and low ADC may allow early diagnosis and treatment. B-D-Glucan levels are also found to be one of the most sensitive markers in some patients with intracranial aspergillosis. Although the function of most intracranial nerves could be regained, the optic nerve was found to have the poorest recovery rate. We recommend prompt complete surgical resection, including curettage, once diagnosed to achieve a better clinical benefit. Anti-fungal agent use should also be considered for precautionary purposes or if complete resection cannot be achieved.

\section{Abbreviations}

ADC: Apparent diffusion coefficient; CNS: Central nervous system;

$\mathrm{CT}$ : Computed tomography; DWl: Diffusion-weighted imaging; MRI: Magnetic resonance imaging; T1Wl: T1-weighted imaging; T2Wl: T2-weighted imaging

\section{Acknowledgements}

We thank all the patients who trusted us with their care and all the clinicians who helped in this study. Special thanks to Christina M. Brown who contributed to the frame and grammar of this article.

\section{Authors' contributions}

$\mathrm{HZ}$ and $\mathrm{XL}$ initiated the study. $\mathrm{HZ}, \mathrm{NJ}$, and $\mathrm{XL}$ collected and analyzed data regarding the clinical data and neuroimaging. $\mathrm{HZ}, \mathrm{XL}$, and JJO wrote the manuscript. NJ and SW were major contributors in revising the manuscript. All authors read and approved the final manuscript.

Funding

Not applicable.

\section{Availability of data and materials}

Data sharing is not applicable to this article as no datasets were generated or analyzed during the current study.

Ethics approval and consent to participate Not applicable.

\section{Consent for publication}

The study has received all related patients' written informed consent.

\section{Competing interests}

The authors declare that they have no competing interests.

\section{Author details}

${ }^{1}$ Department of Neurosurgery, Xiangya Hospital, Central South University, 87 Xiangya Road, Changsha 410008, Hunan, People's Republic of China.

${ }^{2}$ Department of Neurosurgery, Emory University School of Medicine, Atlanta, GA 30322, USA.

Received: 13 January 2020 Accepted: 3 March 2020

Published online: 09 April 2020

\section{References}

1. Endo T, Numagami $Y$, Jokura H, Ikeda H, Shirane R, Yoshimoto T. Aspergillus parasellar abscess mimicking radiation-induced neuropathy. Case report. Surg Neurol. 2001:56(3):195-200.

2. Waitzman AABB. Fungal sinusitis. J Otolaryngol. 1994;23(4):244-9.

3. Lee DH, Yoon TM, Lee JK, Joo YE, Park KH, Lim SC. Invasive fungal sinusitis of the sphenoid sinus. Clin Exp Otorhinolaryngol. 2014;7(3):181-7. 
4. Browning AC, Sim KT, Timms JM, et al. Successful treatment of invasive cavernous sinus aspergillosis with oral itraconazole monotherapy. J Neuroophthalmol. 2006;26(2):103-6.

5. Takahashi $\mathrm{H}$, Hinohira $Y$, Hato $N$, et al. Clinical features and outcomes of four patients with invasive fungal sinusitis. Auris Nasus Larynx. 2011;38(2):289-94.

6. Kumar D, Nepal P, Singh S, et al. CNS aspergilloma mimicking tumors: review of CNS aspergillus infection imaging characteristics in the immunocompetent population. J Neuroradiol. 2018;45(3):169-76.

7. Rosenvald OR, Lessell S. Pupillary sign of aberrant regeneration of the third nerve. Neurology. 2016;86(18):1746.

8. Wang RX, Zhang JT, Chen Y, Huang XS, Jia WQ, Yu SY. Cerebral aspergillosis: a retrospective analysis of eight cases. Int J Neurosci. 2017;127(4):339-43.

9. Brenet E, Boulagnon-Rombi C, N'Guyen Y, Litre CF. Cavernous sinus thrombosis secondary to aspergillus granuloma: a case report and review of the literature. Auris Nasus Larynx. 2016:43(5):566-9.

10. Neil JA, Orlandi RR, Couldwell WT. Malignant fungal infection of the cavernous sinus: case report. J Neurosurg. 2016:124(3):861-5.

11. Chi TH, Chen HS, Yuan CH, Su FM. Acute fulminant invasive fungal sinusitis with cavernous sinus syndrome. J College Physicians Surgeons--Pakistan. 2014;24(Suppl 3):S240-2.

12. Singh $H$, Kandel $R$, Nisar S, Das CJ, Dey AB. An unexpected cause of orbital apex syndrome in an immune-competent elderly male. Oxf Med Case Reports. 2014;2014(6):115-7.

13. Horowitz A, Spendel D, Kraut R, Orentlicher G. Cavernous sinus thrombosis as a result of a fungal infection: a case report. J Oral Maxillofac Surg. 2013; 71(11):1899 e1- e5.

14. Chan JC, Yu DK, Lee DL, Abdullah VJ, Li KK. Combined lateral orbitotomy and endoscopic transnasal orbital decompression in a case of orbital aspergillosis with impending intracranial invasion. Case Rep Ophthalmol. 2012;3(3):418-23.

15. McClelland CM, Wolf RL, Rassekh $\mathrm{CH}$, et al. Monocular vision loss and headache in a 60-year-old liver transplant patient. J Neuroophthalmol. 2012; 32(2):167-71.

16. Lee JC, Lim DJ, Ha SK, Kim SD, Kim SH. Fatal case of cerebral aspergillosis : a case report and literature review. J Korean Neurosurg Soc. 2012;52(4):420-2.

17. Furtado SV, Venkatesh PK, Ghosal N, Hegde AS. Invasive sphenocavernous aspergilloma complicating an operated case of acromegaly. Skull Base Rep. 2011;1(1):33-8

18. Yan B, Wu X, Zhou D. Invasive intracranial aspergillosis in an immunocompetent patient after dental extraction. Scand J Infect Dis. 2011 ; 43(2):156-8.

19. Al-Radadi AM, Alnoury Kl. Optic chiasma involvement secondary to allergic fungal rhinosinusitis. J Pak Med Assoc. 2011;61(7):704-7.

20. Saini J, Gupta AK, Jolapara MB, et al. Imaging findings in intracranial aspergillus infection in immunocompetent patients. World Neurosurgery. 2010;74(6):661-70

21. Wipfler P, Pilz G, Golaszewski S, et al. Invasive aspergillosis presenting with a painless complete ophthalmoplegia. Clin Neurol Neurosurg. 2010;112(1):85-7.

22. Cheung EJ, Scurry WC, Isaacson JE, McGinn JD. Cavernous sinus thrombosis secondary to allergic fungal sinusitis. Rhinology. 2009;47(1):105-8.

23. Chua JL, Cullen JF. Fungal pan-sinusitis with severe visual loss in uncontrolled diabetes. Ann Acad Med Singap. 2008;37(11):964-7.

24. Sasindran V, Ravikumar A, Senthil. Orbital apex syndrome in a child. Indian J Otolaryngol Head Neck Surg 2008; 60(1): 62-65.

25. Akhaddar A, Gazzaz M, Albouzidi A, Lmimouni B, Elmostarchid B, Boucetta M. Invasive Aspergillus terreus sinusitis with orbitocranial extension: case report. Surg Neurol. 2008;69(5):490-5 discussion 5.

26. Freudenstein D, Koerbel A, Beschorner R, Tatagiba M. Successful treatment of aspergillus granuloma involving the cavernous sinus and the middle fossa by using surgery and voriconazole. Case illustration. J Neurosurg. 2007;106(3):511.

27. Baumann A, Zimmerli S, Hausler R, Caversaccio M. Invasive sphenoidal aspergillosis: successful treatment with sphenoidotomy and voriconazole. ORL J Otorhinolaryngol Relat Spec. 2007;69(2):121-6.

28. Stodulski D, Kowalska B, Stankiewicz C. Otogenic skull base osteomyelitis caused by invasive fungal infection. Case report and literature review. Eur Archives Oto-Rhino-Laryngol. 2006;263(12):1070-6.

29. Chopra H, Dua K, Malhotra V, Gupta RP, Puri H. Invasive fungal sinusitis of isolated sphenoid sinus in immunocompetent subjects. Mycoses. 2006;49(1):30-6.

30. Pinzer $T$, Reiss M, Bourquain $H$, Krishnan KG, Schackert G. Primary aspergillosis of the sphenoid sinus with pituitary invasion - a rare differential diagnosis of sellar lesions. Acta Neurochir. 2006;148(10):1085-90 discussion 90.
31. Siraj CA, Krishnan J, Nair RR, Girija AS. Invasive aspergillosis producing painful ophthalmoplegia. J Assoc Physicians India. 2005;53:901-2.

32. Deveze A, Facon F, Latil G, Moulin G, Payan-Cassin H, Dessi P. Cavernous sinus thrombosis secondary to non-invasive sphenoid aspergillosis. Rhinology. 2005;43(2):152-5.

33. Urculo E, Aranzadi MJ, Ruiz I, Villanua J. Aspergillus granuloma of the cavernous sinus: magnetic resonance imaging with pathologic correlation. Acta Neurochir. 2005;147(3):341-2 discussion 2.

34. Petrick M, Honegger J, Daschner F, Feuerhake F, Zentner J. Fungal granuloma of the sphenoid sinus and clivus in a patient presenting with cranial nerve III paresis: case report rand review of the literature. Neurosurgery. 2003;52(4):955-8 discussion 8-9.

35. Safdar A, Dommers MP Jr, Talwani $R$, Thompson CR. Intracranial perineura extension of invasive mycosis: a novel mechanism of disease propagation by Aspergillus fumigatus. Clin Infect Dis. 2002;35(5):e50-3.

36. Hurst RW, Judkins A, Bolger W, Chu A, Loevner LA. Mycotic aneurysm and cerebral infarction resulting from fungal sinusitis: imaging and pathologic correlation. AJNR Am J Neuroradiol. 2001;22(5):858-63.

37. Chandra S, Goyal M, Mishra NK, Gaikwad SB. Invasive aspergillosis presenting as a cavernous sinus mass in immuno competent individuals; report of 3 cases. Neuroradiology. 2000;42(2):108-11.

38. Imai T, Yamamoto T, Tanaka S, et al. Successful treatment of cerebral aspergillosis with a high oral dose of itraconazole after excisional surgery. Intern Med. 1999:38(10):829-32.

39. Takahashi Y, Sugita Y, Maruiwa H, Hirohata M, Tokutomi T, Shigemori M. Fatal hemorrhage from rupture of the intracranial internal carotid artery caused by aspergillus arteritis. Neurosurg Rev. 1998;21(2-3):198-201.

40. Carta A, Cesana C. Ocular presentation and successful outcome of invasive sphenoid sinus aspergillosis in acute myelogenous leukemia. Haematologica. 1998:83(12):1116-9.

41. deShazo RD, O'Brien M, Chapin K, Soto-Aguilar M, Gardner L, Swain R. A new classification and diagnostic criteria for invasive fungal sinusitis. Arch Otolaryngol Head Neck Surg. 1997;123(11):1181-8.

42. Breadmore R, Desmond P, Opeskin K. Intracranial aspergillosis producing cavernous sinus syndrome and rupture of internal carotid artery. Australas Radiol. 1994;38(1):72-5.

43. Fujiwara S, Fujino H, Nogami K, Nishio S, Fukui M. Aspergillosis of the sphenoid sinus with cavernous sinus syndrome. Neuroradiology. 1989;31(5):443.

44. Rowed DW, Kassel EE, Lewis AJ. Transorbital intracavernous needle biopsy in painful ophthalmoplegia. Case report. J Neurosurg. 1985;62(5):776-80.

45. Bikhazi NB, Sloan SH. Superior orbital fissure syndrome caused by indolent Aspergillus sphenoid sinusitis. Otolaryngol--Head Neck Surg. 1998;118(1):102-4.

46. Slavin ML. Primary aspergillosis of the orbital apex. Arch Ophthalmol. 1991; 109(11):1502-3.

47. Okamoto K, Furusawa T, Ishikawa K, Quadery FA, Sasai K, Tokiguchi S. Mimics of brain tumor on neuroimaging: part II. Radiat Med. 2004;22(3):135-42.

48. Friedlander RM, Gonzalez RG, Afridi NA, Pfannl R. Case records of the Massachusetts General Hospital. Weekly clinicopathological exercises. Case 16-2003. A 58-year-old woman with left-sided weakness and a right frontal brain mass. N Engl J Med. 2003;348(21):2125-32.

49. Charlot M, Pialat JB, Obadia N, et al. Diffusion-weighted imaging in brain aspergillosis. Eur J Neurol. 2007;14(8):912-6.

50. Gabelmann A, Klein S, Kern W, et al. Relevant imaging findings of cerebral aspergillosis on MRI: a retrospective case-based study in immunocompromised patients. Eur J Neurol. 2007:14(5):548-55.

51. DeLone DR, Goldstein RA, Petermann G, et al. Disseminated aspergillosis involving the brain: distribution and imaging characteristics. AJNR Am J Neuroradiol. 1999;20(9):1597-604.

52. Leuthardt EC, Wippold FJ 2nd, Oswood MC, Rich KM. Diffusion-weighted MR imaging in the preoperative assessment of brain abscesses. Surg Neurol. 2002;58(6):395-402 discussion.

53. Luthra G, Parihar A, Nath K, et al. Comparative evaluation of fungal, tubercular, and pyogenic brain abscesses with conventional and diffusion MR imaging and proton MR spectroscopy. AJNR Am J Neuroradiol. 2007;28(7):1332-8.

54. Buetow MP, Buetow PC, Smirniotopoulos JG. Typical, atypical, and misleading features in meningioma. Radiographics. 1991;11(6):1087-106.

55. Elster AD, Challa VR, Gilbert TH, Richardson DN, Contento JC. Meningiomas: MR and histopathologic features. Radiology. 1989; 170(3 Pt 1):857-62.

56. Skolnik AD, Loevner LA, Sampathu DM, et al. Cranial nerve Schwannomas: diagnostic imaging approach. Radiographics. 2016;36(5):1463-77. 
57. Ahmadi J, North CM, Segall HD, Zee CS, Weiss MH. Cavernous sinus invasion by pituitary adenomas. AJR Am J Roentgenol. 1986;146(2):257-62.

58. Pisaneschi M, Kapoor G. Imaging the sella and parasellar region. Neuroimaging Clin N Am. 2005;15(1):203-19.

59. Cottier JP, Destrieux C, Brunereau L, et al. Cavernous sinus invasion by pituitary adenoma: MR imaging. Radiology. 2000;215(2):463-9.

60. Yang BT, Chong VF, Wang ZC, Xian JF, Chen QH. Sphenoid sinus ectopic pituitary adenomas: CT and MRI findings. Br J Radiol. 2010;83(987):218-24.

61. Park SB, Lee JH, Weon YC. Imaging findings of head and neck inflammatory pseudotumor. AJR Am J Roentgenol. 2009;193(4):1180-6.

62. Provenzale JM, Mukherji S, Allen NB, Castillo M, Weber AW. Orbital involvement by Wegener's granulomatosis: imaging findings. AJR Am J Roentgenol. 1996;166(4):929-34.

63. Levine SR, Twyman RE, Gilman S. The role of anticoagulation in cavernous sinus thrombosis. Neurology. 1988;38(4):517-22.

64. Visudtibhan A, Visudhiphan P, Chiemchanya S. Cavernous sinus thrombophlebitis in children. Pediatr Neurol. 2001:24(2):123-7.

Ready to submit your research? Choose BMC and benefit from:

- fast, convenient online submission

- thorough peer review by experienced researchers in your field

- rapid publication on acceptance

- support for research data, including large and complex data types

- gold Open Access which fosters wider collaboration and increased citations

- maximum visibility for your research: over $100 \mathrm{M}$ website views per year

At $\mathrm{BMC}$, research is always in progress.

Learn more biomedcentral.com/submissions 